\title{
Role of Cortical Mastoidectomy in the Management of Safe Chronic Otitis Media
}

\author{
Verma $\mathrm{LR}^{1}$, Paudel DR ${ }^{1}$
}

\section{ABSTRACT}

Introduction: Role of cortical mastoidectomy in tympanoplasty for Chronic Otitis Media Mucosal inactive disease is controversial. Some arguments are in favor and suggest that cortical mastoidectomy increases the air reservoir in the mastoid and also help in achieving the patency of aditus but others believe that the ingrowths of squamous epithelium, potential for injury to the inner ear structures and facial nerve during mastoid surgery outweighs the beneficial effects on tympanic membrane healing. Aim: To assess the hearing improvement and graft uptake in patients undergoing Tympanoplasty and Tympano-mastoidectomy in chronic otitis media mucosal inactive disease. Methods: This was a comparative study comprises of 50 patients with Chronic Otitis Media Mucosal inactive ear, conducted in the patients attending the department of ENT in NGMC teaching hospital from Nov 2017 to May 2019. All cases were operated during a period of one half year. 25 patients were selected for tympanoplasty (Group A) and 25 patients were selected for Tympanoplasty with cortical mastoidectomy (Group B). Results: There were 14(28\%) male and 36(72\%) female, with mean age of 28.36 years, ranging from minimum of 13 years to maximum 56 years. The postoperative audiograms were recorded after 3 months. Type I tympanoplasty with cortical mastoidectomy has better graft uptake (96\%) as compared to without mastoidectomy (84\%). Post-operative hearing improvement is almost equal in tympano-mastoidectomy (13.24 dB) and tympanoplasty (13.04 dB). Conclusion: Post-operative hearing gain almost equal in both study group but graft uptake was better with tympano-mastoidectomy then tympanoplasty alone in present study.

Keywords: Chronic Otitis Media (COM), Inactive, Mucosal, Tympanoplasty, Tympano-mastoidectomy.

Authors:

1. Dr. Lok Ram Verma

2. Prof. Dhundi Raj Paudel

${ }^{1}$ Department of Otorhinolaryngology, Nepalgunj Medical College and Teaching Hopital, Banke

\section{Address for Correspondence:}

\author{
Dr. Lok Ram Verma \\ Department of Otorhinolaryngology \\ Nepalgunj Medical College and Teaching Hospital \\ Nepalgunj, Banke, Nepal \\ Email: lokramverma@gmail.com
}

\section{INTRODUCTION}

Otitis media is defined as "an inflammation of the middle ear without reference to etiology or pathogenesis." Otitis media also implies concomitant inflammation, to a greater or lesser extent, of the mastoid air cell system, owing to its anatomic linkage to the middle ear cleft (i.e., the tympanic cavity). Accordingly, otitis media is more correctly conceived of as an inflammatory disorder of the entire tympanomastoid compartment. ${ }^{1}$ It is one of the commonest ear diseases of all age groups and it is caused by multiple interrelated factors including infections, eustachian tube dysfunction, nasal allergy and trauma. The disease Chronic Otitis Media (COM) has been classified on the basis of its underlying pathology as active or inactive mucosal, active or inactive squamous and healed chronic otitis media. ${ }^{2}$ According to Jackler and Schindler many factors contribute to success or failure of surgery which are divided into mastoid and non-mastoid factors. ${ }^{3}$ Non mastoid factors are age, general debility, and eustachian tube dysfunction, septic focus in non-mastoid areas, cochlear reserve and ossicular chain status. Mastoid factors are extent of pneumatization and presence of inflammatory disease in mastoid. Holmquist and Bergstorm in 1978 said that well aerated mastoid is a prerequisite for well ventilated middle ear and long lasting success. ${ }^{4}$ The term tympanoplasty was first used in 1953 by Wullstein to describe surgical techniques for reconstruction of the middle ear hearing mechanism that had been impaired or destroyed by chronic ear disease. ${ }^{5}$ Role of cortical mastoidectomy in tympanoplasty for COM Mucosal inactive disease is controversial. Those arguing in favor suggest that cortical mastoidectomy increases the air reservoir in the mastoid and also help in achieving the patency of aditus but the rationale use for the addition of simple mastoidectomy to tympanoplasty does not universally accepted, with the fear that an unoccluded antrum would invite the ingrowths of squamous epithelium. Others believe that the potential for injury to the inner ear structures and facial nerve during mastoid surgery outweighs the beneficial effects on tympanic membrane healing. ${ }^{6}$ 
The aim of this study is:

1. To assess the graft uptake in patients undergoing tympanoplasty and Tympanomastoidectomy in COM mucosal inactive disease.

2. To compare the hearing improvement in patients undergoing tympanoplasty and Tympanomastoidectomy in COM mucosal inactive disease.

\section{METHODS}

The present prospective study was conducted in the Department of Otorhinolaryngology, Nepalgunj Medical College, Teaching Hospital Nepalgunj, Banke, Nepal. The total number of cases included in the study was 50. A detailed history followed by general physical and detailed ENT examination was done in all patients and diagnosis recorded. These cases were subjected to routine investigations (Complete Blood count and Urine analysis) and specific investigations. Pure Tone Audiometry (PTA) was done by ALPS Advanced Digital Audiometer AD 2100 in a sound proof room. Otomicroscopy was done to reconfirm the otoscopic finding, middle ear mucosal status, middle ear epithelization and status of attic region. All patients had undergone X-ray Mastoid Schuller's view to see for the status of pneumatization of mastoid and findings were recorded as well pneumatized and sclerotic. Depending on the clinical diagnosis and mastoid pneumatization of the patient they were divided into two groups.

- Group A - 25 patients underwent tympanoplasty.

- Group B-25 patients underwentTympano-mastoidectomy.

Written and informed consent was taken before surgery. Ethical clearance was obtained from IRC (NGMC). Tympanoplasty and tympanomastoidectomy was done. Patient was watched for soakage of dressing, vertigo, facial nerve status, otalgia, headache etc. and discharged on $2^{\text {nd }}$ day after re-dressing. First visit was at 7 post-op days for removal of dressing, cotton/ ribbon plug and stitches. Patients were advised to start a topical antibiotic ear drops for two weeks. Second visit was done at 21 post-op days for, subjective evaluation (hearing, tinnitus, and any other complaints) and status of post aural wound. Third visit was done at one and half month postoperative day for subjective evaluation (hearing, tinnitus, and any other complaints) and post aural wound and status of graft by otoscopy. Fourth visit was at 3 months post op for subjective evaluation and PTA was repeated. These findings were then evaluated and compared with preoperative findings.

\section{RESULTS}

\section{Age and Sex Incidence}

The study conducted in the patients attending the department of ENT in NGMC teaching hospital from November 2017 to May 2019. During the period under study, a total of 50 patients with established chronic otitis media inactive were studied.
$14(28 \%)$ were males and 36(72\%) females. Their ages ranged from 13 year to 56 years with mean age was $28.36 \pm 11.56$ days. Patients in the age group of $10-20$ years were $16(32 \%)$, followed by $21-30$ were $17(34 \%), 31-40$ were $9(18 \%), 41-50$ were $5(10 \%)$ and $>50$ were $3(6 \%)$.

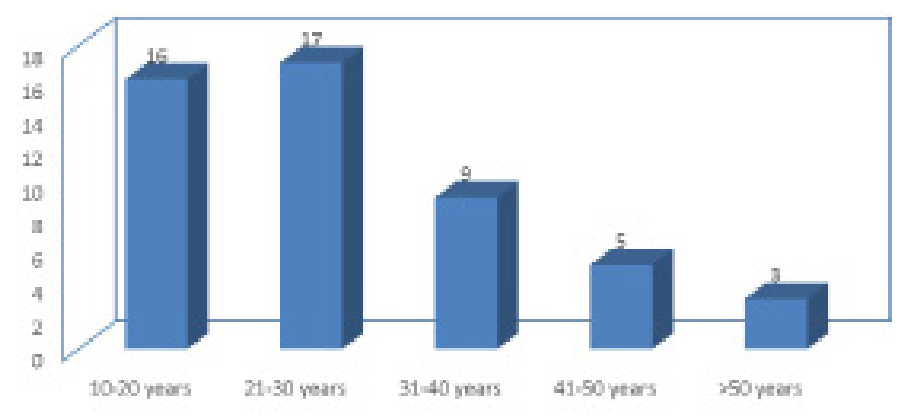

Figure 1 : Age distribution

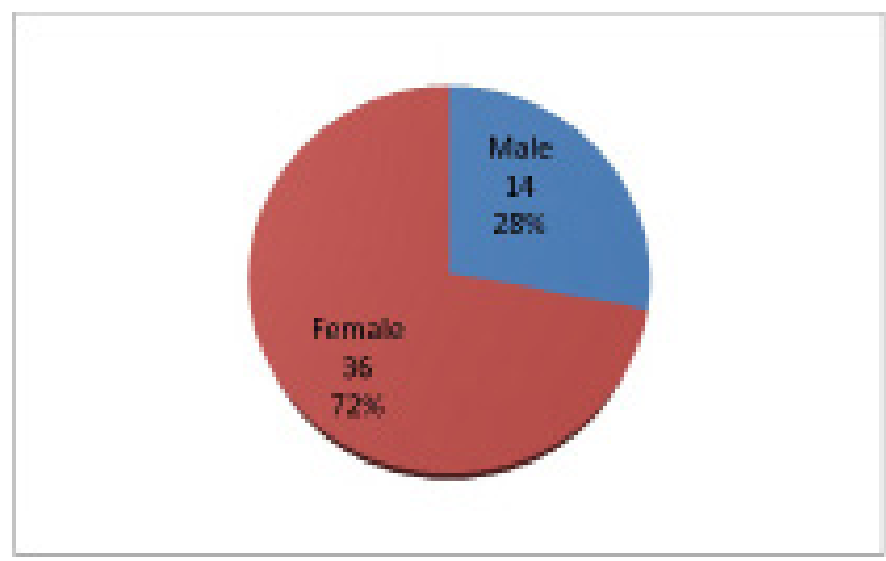

Figure 2 : Sex distribution

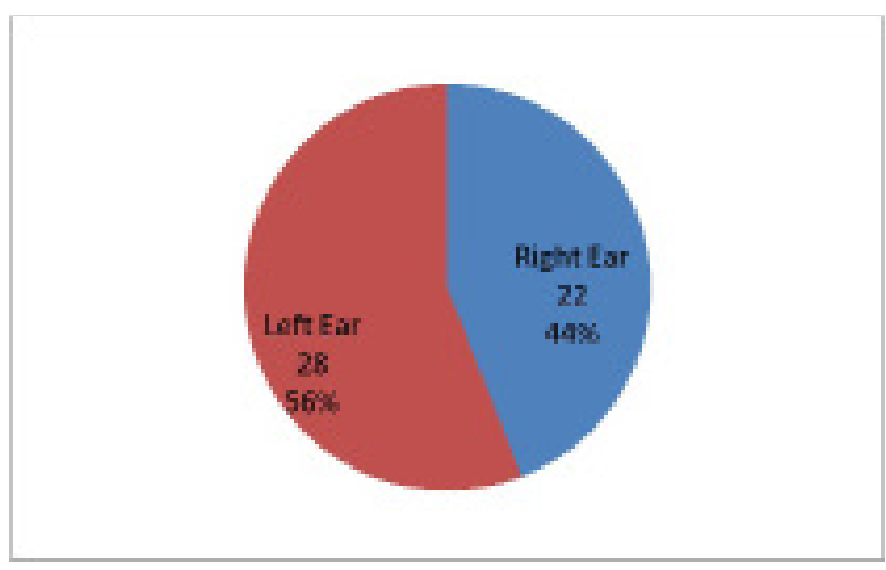

Figure 3 : Laterality

\section{Ear Involved}

Figure 3 show that right ear involvement was seen in 22(44\%) cases. The left ear was seen to be involved in $28(56 \%)$ of the cases. Out of the 50 cases, the disease was unilateral in $39(78 \%)$ patients and bilateral in $11(22 \%)$ patients. 


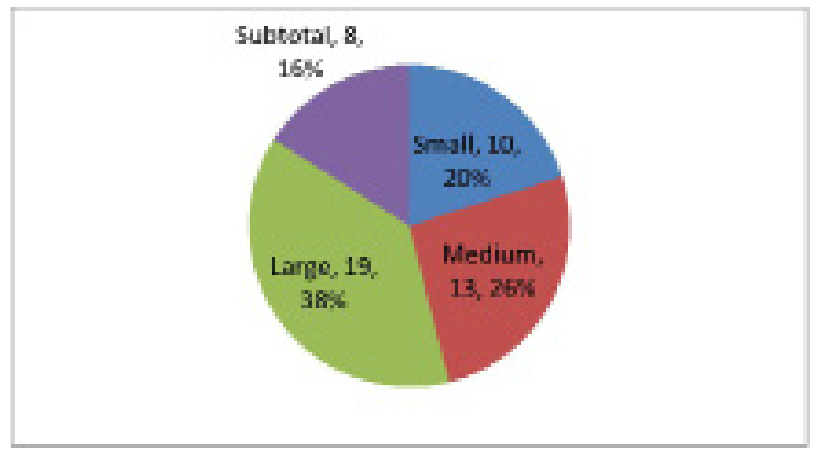

Figure 4 : Type of perforation

\section{Size of Perforation}

Figure 4 show the type of perforation. Large perforation was seen in 19 (38\%), followed by medium perforation $13(26 \%)$, small perforation $10(20 \%)$ and subtotal perforations was seen in $8(10 \%)$ of the patients.

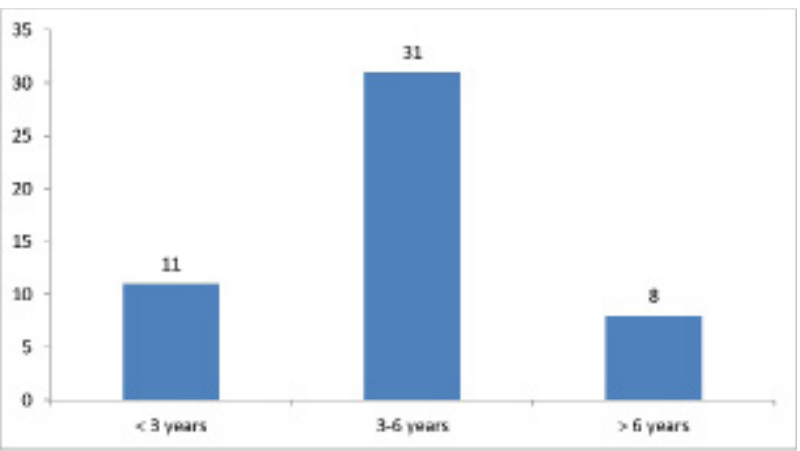

Figure 5 : Duration of Ear Discharge

\section{Duration of Ear Discharge}

Figure 5 show duration of ear discharge. In maximum number of patients, 31(62\%), the duration of ear discharge was 3-6 years, followed by $11(22 \%)$ and $8(16 \%)$ of the patients where the duration was seen to be $<3$ and $>6$ years respectively.

\section{Pre-op Audiological Assessment}

The preoperative AC threshold was $(43.44 \pm 4.34)$ for Group " $A$ " patients undergoing tympanoplasty and (36.16 \pm 4.39 ) for Group "B" patients undergoing Tympano-mastoidectomy (Table I). In present study preoperative mean A-B gap in Groups A and B was $(21.36 \pm 3.12 \mathrm{~dB})$ and $(21.64 \pm 3.06 \mathrm{~dB})$ respectively.

\begin{tabular}{|ccc|}
\hline Group & A & B \\
\hline Pre-op AC Threshold (mean \pm SD) & $43.44 \pm 4.34$ & $36.16 \pm 4.39$ \\
\hline Pre-op AB Gap (mean \pm SD) & $21.36 \pm 3.12$ & $21.64 \pm 3.06$
\end{tabular}

Table I: Pre-op Audiological Assessment

\section{Mastoid Pneumatization}

Radiologic condition was noted in every patient. Pneumatic mastoid was observed in $9(18 \%)$ patients and sclerotic mastoid in $41(82 \%)$ patients. In group " $\mathrm{A}$ " Pneumatic mastoid was
$7(28 \%)$ patients and sclerotic mastoid 18 (72\%) patients. In group " $\mathrm{B}$ " Pneumatic mastoid was 2 (8\%) patients and sclerotic mastoid 23 (92\%) patients.

\section{Graft Uptake}

Table II shows the status of graft after 3 months follow up. Results were taken as positive if graft was taken up and negative if it was not taken up. It shows that in Group " $A$ " graft take up rate was 21(84\%) and in Group "B" it was 24(96\%).

\begin{tabular}{|cccc|}
\hline Group & A & B & P value \\
\hline Positive & 21 & 24 & \\
& $(84 \%)$ & $(96 \%)$ & \\
\hline Negative & 4 & 1 & 0.157 \\
\hline
\end{tabular}

Table II : Graft Uptake

\section{Post-op Audiological Assessment}

Postoperatively AC hearing threshold was $(26.40 \pm 1.29 \mathrm{~dB})$ in Group A and ( $26.92 \pm 2.19 \mathrm{~dB})$ in Group B. The average gain in air conduction threshold was $13.04 \pm 6.54$ in patients who had undergone tympanoplasty while the gain seen in patients who had undergone Tympano-mastoidectomy was $13.24 \pm 5.52$. However this was not statistically significant (Table III). In this study preoperative mean A-B gap in Groups A and B was (21.36 $\pm 3.12 \mathrm{~dB})$ and $(21.64 \pm 3.06 \mathrm{~dB})$ respectively. Postoperatively mean $A B$ gap was $(12.00 \pm 1.63 \mathrm{~dB})$ in Group $A$ and $(11.92 \pm$ $2.85 \mathrm{~dB})$ in Group B. Overall $A B$ gap gain was $(9.36 \pm 3.77 \mathrm{~dB})$ for Group A and ( $9.72 \pm 3.75 \mathrm{~dB}$ ) for Group B (Table IV).

\begin{tabular}{|cccc|}
\hline Group & A & B & P-value \\
\hline Pre-op AC Threshold & $43.44 \pm 4.34$ & $36.16 \pm 4.39$ & 0.00 \\
\hline Post-op AC Threshold & $26.40 \pm 1.29$ & $26.92 \pm 2.19$ & 0.313 \\
\hline AC Threshold gain & $13.04 \pm 6.54$ & $13.24 \pm 5.52$ & 0.914 \\
\hline
\end{tabular}

Table III : Post-op Audiological Assessment (AC Threshold)

\begin{tabular}{|cccc|}
\hline Group & A & B & P-value \\
\hline Pre-op A-B Gap & $21.36 \pm 3.12$ & $21.64 \pm 3.06$ & 0.750 \\
\hline Post-op A-B Gap & $12.00 \pm 1.63$ & $11.92 \pm 2.85$ & 0.904 \\
\hline A-B Gap gain & $9.36 \pm 3.77$ & $9.72 \pm 3.75$ & 0.737 \\
\hline
\end{tabular}

Table IV : Post-op Audiological Assessment (A-B Gap)

\section{DISCUSSION}

In the present study, 50 patients in the age group of $13-56$ years of either sex were selected from Ear, Nose and Throat Outpatient Department of NGMC, Nepalgunj Teaching Hospital, Nepalgunj. A detailed history, clinical examination and investigations were done as per the performa. Pure tone audiometery was done to assess hearing loss before and 3 month after surgery. 


\section{Age \& Sex Incidence:}

In this study, the age group ranged from 13 to 65 years with maximum number of patients 17 being between the age group of 21-30 years followed by 16 patients between age group 10-20 years. The mean age of patients in our study was 28 years. In a study done by Chavan et al, the mean age of presentation was also 28 years ${ }^{6}$. In present study there was female preponderance as compared to male patients. Overall $36(72 \%)$ were females while rest $14(28 \%)$ patients was males.

\section{Ear Involved:}

The right ear involvement was seen in $22(44 \%)$ cases. The left ear was seen to be involved in $28(56 \%)$ of the cases. Out of the 50 cases, the disease was unilateral in $39(78 \%)$ patients and bilateral only in $11(22 \%)$ patients.

\section{Duration of Ear Discharge:}

The duration of ear discharge ranged from 2 years to 9 years. Maximum number of patients, that were $31(62 \%)$ cases, had duration of ear discharge of 3-6 years fallowed by $11(22 \%)$ patients gave history of ear discharge for a duration of $<3$ year and $8(16 \%)$ had a history of ear discharge of $>6$ years. In a study conducted by Kabdwal et al. $37.5 \%$ of the patients presented with a history of ear discharge for 10-15 years. ${ }^{7}$ Longer duration of ear discharge shows lack of awareness about the disease and its complications.

Present study revealed that the most common type of perforation seen was large perforation, seen in 19(38\%), followed by medium perforation $13(26 \%)$, small perforation $10(20 \%)$ and subtotal perforations seen in $8(10 \%)$ of the patients.

\section{Radiological Condition of Mastoid:}

Radiologic condition was noted in every patient. Pneumatic mastoid was observed in $9(18 \%)$ patients and sclerotic mastoid in $41(82 \%)$ patients of the patients in our study, while $93 \%$ of the patients in the study done by Sharma et al. were observed to have a sclerotic mastoid ${ }^{7}$.

Graft Uptake In the present study, the success was defined as intact graft at least 3 months postoperatively. The success rate was in terms of graft uptake rate which was $84 \%$ with tympanoplasty, and $96 \%$ with Tympano-mastoidectomy. These findings were consistent with those of the study done by Chavan et al. ${ }^{6}$ it was observed that the success rate of graft uptake was also seen to be $100 \%$ with Tympano-mastoidectomy in the studies conducted by Sharma et al. ${ }^{7}$ and Nayak et al. ${ }^{8}$ However in the study conducted by Yasuo et al. ${ }^{9}$ the graft uptake was seen to be slightly better with tympanoplasty $(94.4 \%)$ than with Tympano-mastoidectomy (90.7\%).

\begin{tabular}{|cccc|}
\hline Study & No of cases & $\begin{array}{c}\text { Group A } \\
\text { Tympanoplasty }\end{array}$ & $\begin{array}{c}\text { Group B Tympano- } \\
\text { mastoidectomy }\end{array}$ \\
\hline Present Study & 50 & $84 \%$ & $96 \%$ \\
\hline Chaven et al & 150 & $93.3 \%$ & $97.3 \%$ \\
\hline Sharma et al & 40 & $95 \%$ & $100 \%$ \\
\hline Nayak et al & 40 & $60 \%$ & $100 \%$ \\
\hline Yasuo et al & 251 & $94.4 \%$ & $90.7 \%$ \\
\hline & & Table V : Graft Intake & \\
& &
\end{tabular}

\section{Hearing Improvement}

In present study, we observed that the hearing gain in patients undergoing Tympano-mastoidectomy was $13.24 \mathrm{~dB}$ and the gain seen in patients undergoing tympanoplasty was $13.04 \mathrm{~dB}$. This was seen to be statistically significant up to a level of $5 \%$. According to a study conducted by Kabdwal et al. ${ }^{10}$ the average hearing gain in patients who underwent tympanoplasty alone was $7.8 \mathrm{~dB}$ and the gain in patients who underwent Tympanomastoidectomy was $3.5 \mathrm{~dB}$. In the study, conducted by Sharma et al. $^{7}$ the hearing gain in patients underwent Tympanomastoidectomy was $20.48 \mathrm{~dB}$ and the gain seen in patients underwent tympanoplasty was $15.75 \mathrm{~dB}$. Table VI.

\begin{tabular}{|cccc|}
\hline \multicolumn{1}{|c}{ Study } & No. of cases & $\begin{array}{c}\text { Group A } \\
\text { Tympanoplasty }\end{array}$ & $\begin{array}{c}\text { Group B Tympano- } \\
\text { mastoidectomy }\end{array}$ \\
\hline Present study & 50 & $13.04 \mathrm{~dB}$ & $13.24 \mathrm{~dB}$ \\
\hline Kabdwal et al. & 57 & $7.80 \mathrm{~dB}$ & $3.50 \mathrm{~dB}$ \\
\hline Sharma et al. & 40 & $15.75 \mathrm{~dB}$ & $20.48 \mathrm{~dB}$ \\
\hline & \multicolumn{3}{c}{ Table VI : Hearing improvement } \\
\end{tabular}

In our study preoperative mean $A-B$ gap in Groups $A$ and $B$ was $(21.36 \pm 3.12 \mathrm{~dB})$ and $(21.64 \pm 3.06 \mathrm{~dB})$ respectively. Postoperatively mean $A B$ gap was $(12.00 \pm 1.63 \mathrm{~dB})$ in Group $A$ and $(11.92 \pm 2.85 \mathrm{~dB})$ in Group B. Overall AB gap gain was $(9.36 \pm$ 3.77dB) for Group A and (9.72 \pm 3.75$)$ for Group B. Hence there was a significant improvement seen in the ABG in both group in our study. The average gain in air conduction threshold was $13.04 \pm 6.54$ in patients who had undergone tympanoplasty while the gain seen in patients who had undergone Tympanomastoidectomy was $13.24 \pm 5.52$. However this was not statistically significant.

\section{LIMITATION}

To establish strong indication and statistical significance about role of mastoidectomy the management of safe Chronic Otitis Media, it requires large sample size and multicenter study.

\section{CONCLUSION}

Depending on our observation we concluded that hearing improvement are equal in both study group. However tympanomastoidectomy may have beneficial effect on the post-operative healing and graft uptake. To establish strong indication and statistical significance about role of mastoidectomy, it requires large sample size and multicenter study. 


\section{REFERENCES}

1. Wullstein H (2003) Tympanoplasty. In: Glasscock ME, Shambaugh GE (eds) Surgery of the Ear, 5th edn. Elsevier, Hamilton, p 422.

2. Browning GG, Merchant SN, Kelly G, Swan RC, Canter R, Mckerrow WS (2008) Chronic otitis media. In: Gleeson $M$, Browning GG, Burton MJ, Clarke RW, Hibbert J, Jones NS, Lund VJ, Luxon L, Watkinson JC (eds) Scott-Brown's otorhinolaryngology, head and neck surgery, vol 3, 7th edn. Edward Arnold Publishers Ltd, London, p 3395.

3. Jackler S (1983) Myringoplasty with simple mastoidectomy: results in eighty two consecutive patients. Otolaryngol Head Neck Surg 91:14-17

4. Holmquist J, Bergstorm B (1978) Mastoid air cell system in ear surgery. Arch Otolaryngol Head Neck Surg 104:127-129

5. Wullstein H (2003) Tympanoplasty. In: Glasscock ME, Shambaugh GE (eds) Surgery of the Ear, 5th edn. Elsevier, Hamilton, p 463

6. Chavan S, Deshmukh S, Pawar V, Kirpan V, Khobragade S, Sarvade K (2011) Tympanoplasty with and without cortical mastoidectomy for tubotympanic type of chronic suppurative otitis media. Otolaryngol Head Neck Surg 8(1):8-10

7. Akriti Sharma, Nitish Baisakhiya, L. N. Garg, Gurchand Singh (2016) Evaluation of Role of Mastoid Surgery in the Management of Safe Chronic Suppurative Otitis Media. Indian J Otolaryngol Head Neck Surg 68(4):434-440.

8. Nayak DR, Balakrishnan R, Hazarika P, Mathew PT (2003) Role of cortical mastoidectomy in the results of myringoplasty for dry tubotympanic disease. Indian J Otol 9:11-15

9. Yasuo M, Masafumi S, Yoshifumi T, Kitahara T, Kajikawa H, Takeshi K (2001) Tympanoplasty with and without mastoidectomy for non-cholesteatomatous chronic otitis media. Eur Arch Otorhinolaryngol 258(1):13-15

10. Kabdwal N, Varshney S, Bist SS, Bhagat S, Mishra S, Agarwal V (2013) Pre and post-operative evaluation of hearing in chronic suppurative otitis media. Indian J Otol 19:164-168

11. Goyal R (2010) Role of cortical mastoidectomy in type I tympanoplasty. Indian J Otol 16:8-12 